\title{
Flow Control for a Two-Stage Proportional Valve with Hydraulic Position Feedback
}

\author{
He Wang ${ }^{1,2}$, Xiaohu Wang ${ }^{1}$, Jiahai Huang ${ }^{1}$ and Long Quan ${ }^{1 *}$ []
}

\begin{abstract}
The current research mainly focuses on the flow control for the two-stage proportional valve with hydraulic position feedback which is named as Valvistor valve. Essentially, the Valvistor valve is a proportional throttle valve and the flow fluctuates with the change of load pressure. The flow fluctuation severely restricts the application of the Valvistor valve. In this paper, a novel flow control method the Valvistor valve is provided to suppress the flow fluctuation and develop a high performance proportional flow valve. The mathematical model of this valve is established and linearized. Fuzzy proportional-integral-derivative (PID) controller is adopted in the closed-loop flow control system. The feedback is obtained by the flow inference with back-propagation neural network (BPNN) based on the spool displacement in the pilot stage and the pressure differential across the main orifice. The results show that inference with BPNN can obtain the flow data fast and accurately. With the flow control method, the flow can keep at the set point when the pressure differential across the main orifice changes. The flow control method is effective and the Valvistor valve changes from proportional throttle valve to proportional flow valve. For the developed proportional flow valve, the settling time of the flow is very short when the load pressure changes abruptly. The performances of hysteresis, linearity and bandwidth are in a high range. The linear mathematical model can be verified and the assumptions in the system modeling is reasonable.
\end{abstract}

Keywords: Flow control, Proportional valve, Hydraulic position feedback, Back-propagation neural network

\section{Introduction}

Proportional valves are widely used in hydraulic systems of various machines and devices. Their main task is to control the motion of hydraulic actuators. Single stage proportional valves can only be used in the small flow conditions owing to the performance limitation of electromagnet, while two-stage proportional valves can be used in the large flow conditions $[1,2]$. In the two-stage proportional valves, the feedback types for proportional control include electric position feedback, force position feedback and hydraulic position feedback [3-5]. The twostage proportional valve with hydraulic position feedback was originally developed by Andersson. In this valve,

\footnotetext{
*Correspondence: quanlong@tyut.edu.cn

${ }^{1}$ Key Laboratory of Advanced Transducers and Intelligent Control System, Ministry of Education, Taiyuan University of Technology, Taiyuan 030024, China

Full list of author information is available at the end of the article
}

a very small pilot flow is used to actuate the large main flow. The main flow is an amplification of the pilot flow. The behavior of the valve is similar to an electronic transistor, hence this valve is named as Valvistor valve $[6,7]$. Because of the superiorities of low production costs, simple construction and strong reliability, this valve shows a broad application prospect. In recent years, the valves that use the Valvistor principle have been produced by the Eaton Corporation in the United States, a world famous hydraulic component manufacturer.

Although the Valvistor valve is a popular industrial product, it has an inherent defect. It is a proportional throttle valve and the spool displacement is the controlled object [8]. In addition to the input voltage, the flow is also affected by the change of load pressure [9, 10]. Thus, it can only be applied in the conditions where the requirement for the accuracy of flow is low or the load pressure is constant. However, in many industrial
Springer Open

(c) The Author(s) 2020. This article is licensed under a Creative Commons Attribution 4.0 International License, which permits use, sharing, adaptation, distribution and reproduction in any medium or format, as long as you give appropriate credit to the original author(s) and the source, provide a link to the Creative Commons licence, and indicate if changes were made. The images or other third party material in this article are included in the article's Creative Commons licence, unless indicated otherwise in a credit line to the material. If material is not included in the article's Creative Commons licence and your intended use is not permitted by statutory regulation or exceeds the permitted use, you will need to obtain permission directly from the copyright holder. To view a copy of this licence, visit http://creativeco mmons.org/licenses/by/4.0/. 
applications, the velocity of hydraulic actuators must be precisely controlled when the load pressure changes [1113]. This need to make the flow unaffected by the change of load pressure. As a result, the application of the Valvistor valve is limited to a rather narrow range due to this inherent disadvantage.

To solve this problem, researchers put forward some different methods based on the characteristic of the Valvistor valve that the main flow is an amplification of the pilot flow, and attempt to obtain the pilot flow which is not affected by the change of the load pressure. Eriksson arranged a mechanical pressure compensator between the pilot stage and the main stage to maintain a constant pressure differential across the pilot stage and the pilot flow is independent to the load pressure [14]. Hao et al. [15] used a hydraulic pump with small displacement to regulate the pilot flow by changing the pump speed, then the impact of pressure differential change on the flow can be counteracted. Huang et al. [16] presented a digital pressure compensator and the spool displacement of the pilot stage is adjusted based on the pressure differential across the pilot stage, so that the pilot flow can be precisely controlled. The common characteristic of these methods is regarding the pilot flow as the controlled object and the flow is under indirect control. However, the amplification factor between the main flow and the pilot flow is so uncertain that it cannot even be accurately calculated or predicted, because it is influenced by many disturbance factors, such as pressure fluctuation, machining error, flow force [17-19]. Consequently, these methods are not very effective and the flow accuracy is still poor.

It is certain that regarding the flow as the controlled object and controlling it directly can improve the flow accuracy [20]. However, this will bring an issue that how to measure the flow through this valve fast and accurately and use it as the feed-back. Usually, there are two methods for metering the flow through a valve [21]. The first method is metering the flow with flow meter directly. This method is accurate, but greatly lagging because the response of flow meter is slow [22]. The second method is metering the pressure differential and spool displacement, then the flow can be computed with the flow equation. This method is fast enough, but rather imprecise due to the indeterminacy of the discharge coefficient [23]. Therefore, these two methods cannot be applied to this case. Measuring the flow through this valve fast and accurately become the bottleneck of direct control for the flow.

Artificial neural network is an information processing system simulating the biological neural network of the brain by interconnecting artificial neurons and has been widely used in practice. Back-propagation neural network (BPNN) is a representative learning model for the artificial neural network [24]. Accurate inference with BPNN have been frequently concerned by researchers [25]. Many research achievements have been applied to many industry fields [26-28]. This brings a good inspiration for measuring the flow fast and accurately. The flow through a hydraulic valve can be precisely inferred according to the pressure differential and spool displacement. This nicely copes with the problem encountered in flow control for this valve that is measuring the flow fast and accurately.

Proportional-integral-derivative (PID) controller is a commonly used control loop feedback mechanism which continuously calculates the error between the desired value and the measured value, and conducts the correction based on proportional, integral, and derivative terms [29]. Fuzzy PID controller is a type of PID controller, in which the PID coefficients can be tuned automatically based on the fuzzy logic [30]. The fuzzy PID controller provide more accurate results in non-linear situations compared with the standard PID controller and has been successfully applied in the flow control [31-33].

Motivated by the above observations, the present study mainly concentrates on the flow control for the twostage proportional valve with hydraulic position feedback which is named as Valvistor valve. In this paper, a novel flow control method for the Valvistor valve is provided. Fuzzy PID controller is adopt in the closed-loop flow control system. The feedback is obtained by the flow inference with BPNN based on the spool displacement in the pilot stage and the pressure differential across the main orifice. By this method, the flow is precisely controlled and unaffected by the change of load pressure. The aim is to develop a high performance two-stage proportional flow valve based on the Valvistor valve.

\section{System Modelling}

The schematic diagram of the Valvistor valve is shown in Figure 1. The Valvistor valve can be categorized into two-stage proportional valve. The poppet valve serves as the main stage and the solenoid operated proportional spool valve serves as the pilot stage. The channel inside the poppet and the slot on the side surface of the poppet close the hydraulic position feedback loop which is used to control the poppet displacement. The poppet displacement is proportional to the orifice area formed by the slot and valve body. There is an underlap in the slot, so that the oil can flow into the upper cavity of the main stage when the main orifice closes.

As shown in Figure 1a, when there is no signal input in the proportional solenoid and the pilot orifice closes, the upper cavity of the main stage is only connected to the inlet. The pressure in the upper cavity of the main 


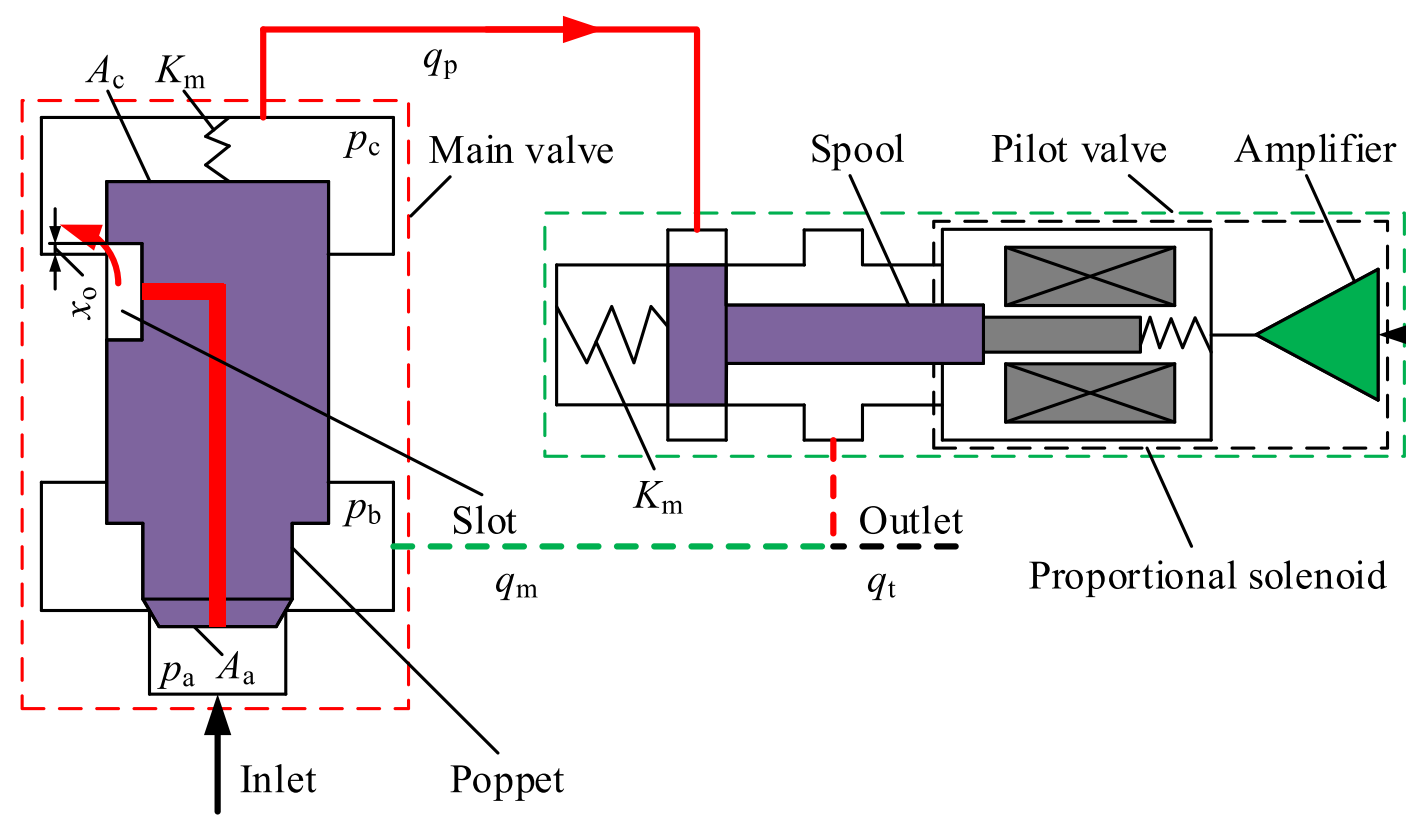

$\mathbf{a}$

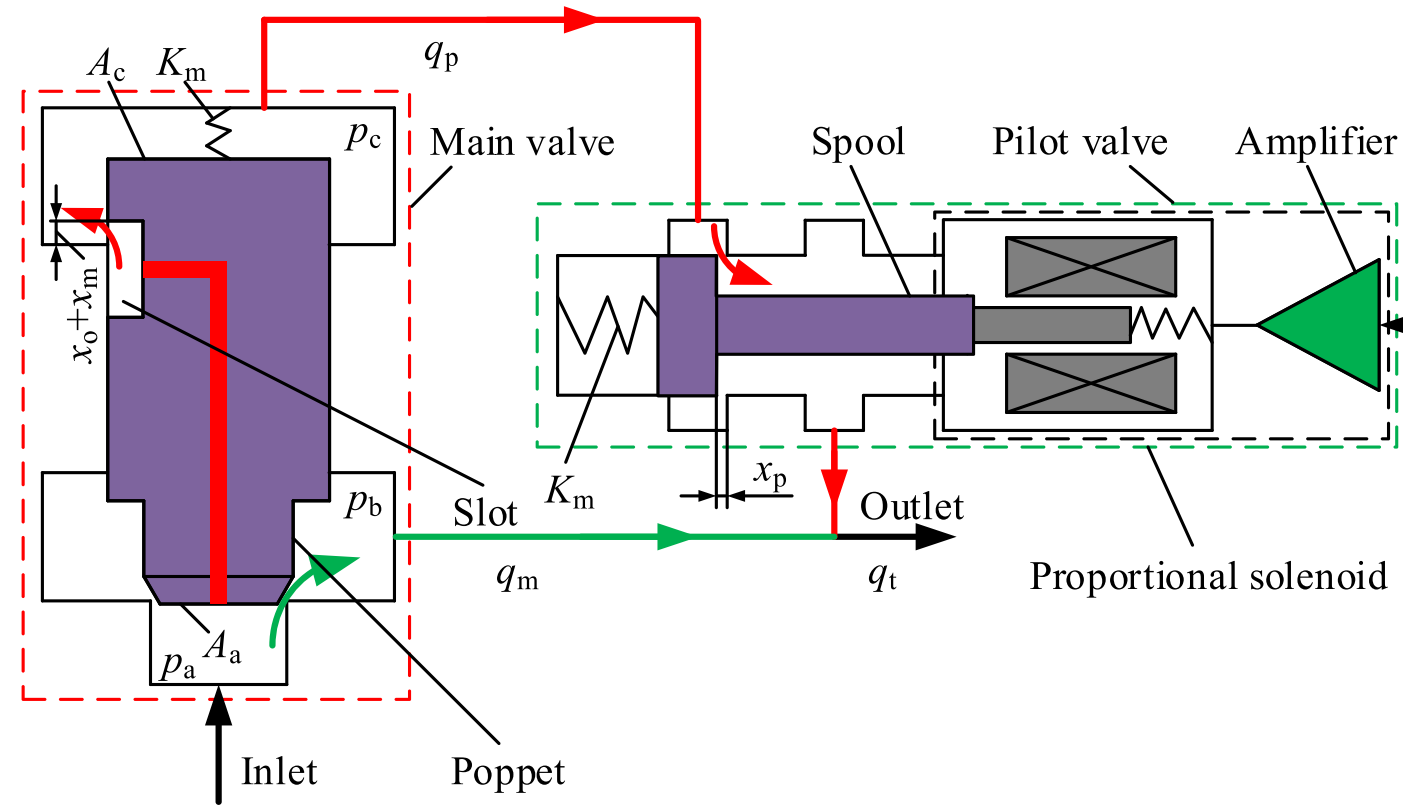

b

Figure 1 Schematic diagram of the Valvistor valve: a No voltage signal input, and $\mathbf{b}$ voltage signal input

stage $p_{\mathrm{c}}$ is equal to the inlet pressure $p_{\mathrm{a}}$ when the oil flows into the upper cavity through the underlap in the slot $x_{0}$. The force acting on the top of the poppet is larger than the force acting on the bottom of the poppet, because the inlet pressure $p_{\mathrm{a}}$ is larger than the outlet pressure $p_{\mathrm{b}}$. Thus the main orifice closes.

As shown in Figure 1b, when the proportional solenoid receives voltage signal $u$ and opens the pilot orifice, the 
upper cavity of the main stage is connected to both the inlet and the outlet. The oil flow through the pilot stage leads to a pressure differential across the main stage and consequently causes the poppet to move. When under steady state condition, the flow equilibrium generates slot orifice area. The force equilibrium generates the pressure in the upper cavity of the main stage $p_{\mathrm{c}}$. The orifice area formed by the slot and valve body which is proportional to the poppet displacement $x_{\mathrm{m}}$ is controlled by the pilot orifice. As a result, the main flow $q_{\mathrm{m}}$ is controlled by the pilot orifice. In addition, the pilot flow $q_{\mathrm{p}}$ converges with the main flow $q_{\mathrm{m}}$ so as to increase the efficiency of hydraulic system.

To simplify the analysis, there are some reasonable assumptions in the system modeling. The assumptions are summarized as follows. (1) The flow force is neglected because researchers have confirmed that the effect of flow force on the Valvistor valve performance is rather weak. In the analysis related to the Valvistor valve, researchers have given convincing results with neglected flow force $[6,16]$. (2) The solenoid dynamics is ignored as it is fast enough. Researchers have established mathematical model of the Valvistor valve with ignored solenoid dynamics and the results are validated by experiments [17]. (3) The pilot stage dynamics is ignored because the spool mass is rather small and spring stiffness is relatively high $[6,17]$. (4) Flow in this valve is assumed to be turbulent because it has been certified that turbulent flow occurs at high Reynolds numbers in the poppet valve and spool valve [16]. (5) The effect of temperature on fluid properties is neglected and liquid properties are constant [15]. (6) The oil in this valve is incompressible and the leakage of this valve is omitted [14].

In the pilot stage, the force balance on the spool can be expressed as

$$
k_{\mathrm{e}} u=k_{\mathrm{p}} x_{\mathrm{p}},
$$

where $k_{\mathrm{e}}$ denotes the gain of the proportional solenoid, $u$ denotes the input voltage, $k_{\mathrm{p}}$ denotes the proportion coefficient, and $x_{\mathrm{p}}$ denotes the spool displacement in the pilot stage. When the input signal opens the pilot orifice, the fluid is allowed to flow through the pilot stage and the flow can be calculated as

$$
q_{\mathrm{p}}=C_{\mathrm{dp}} \omega_{\mathrm{p}} x_{\mathrm{p}} \sqrt{\frac{2\left(p_{\mathrm{c}}-p_{\mathrm{b}}\right)}{\rho}},
$$

where $q_{\mathrm{p}}$ is the pilot flow, $C_{\mathrm{dp}}$ is the discharge coefficient of the pilot orifice, $\omega_{\mathrm{p}}$ is the area gradient of the pilot orifice, $x_{\mathrm{p}}$ is the spool displacement in the pilot stage, $p_{\mathrm{c}}$ is the pressure in the upper cavity of the main stage, $p_{\mathrm{b}}$ is the outlet pressure, and $\rho$ is the oil density. Whenever the pilot orifice opens, the fluid is allowed to flow through the slot on the side surface of the poppet. According to the flow equilibrium, the pilot flow can also be expressed as

$$
q_{\mathrm{p}}=q_{\mathrm{s}}=C_{\mathrm{ds}} \omega_{\mathrm{s}}\left(x_{\mathrm{o}}+x_{\mathrm{m}}\right) \sqrt{\frac{2\left(p_{\mathrm{a}}-p_{\mathrm{c}}\right)}{\rho}},
$$

where $q_{\mathrm{s}}$ is flow through the slot orifice, $C_{\mathrm{ds}}$ is the discharge coefficient of the slot orifice, $\omega_{\mathrm{s}}$ is the area gradient of the slot orifice, $x_{\mathrm{o}}$ is the underlap of the slot orifice, $x_{\mathrm{m}}$ is the poppet displacement in the main stage, and $p_{\mathrm{a}}$ is the inlet pressure.

In the main stage, the force equilibrium on the poppet can be described as

$$
A_{\mathrm{a}} p_{\mathrm{a}}+\left(A_{\mathrm{c}}-A_{\mathrm{a}}\right) p_{\mathrm{b}}-A_{\mathrm{c}} p_{\mathrm{c}}=m_{\mathrm{m}} \ddot{x}_{\mathrm{m}}+B_{\mathrm{m}} \dot{x}_{\mathrm{m}}+k_{\mathrm{m}} x_{\mathrm{m}},
$$

where $A_{\mathrm{a}}$ denotes the area at the top of the poppet, $A_{\mathrm{c}}$ denotes the area at the bottom of the poppet, $m_{\mathrm{m}}$ denotes the poppet mass, $B_{\mathrm{m}}$ denotes the viscous damping coefficient in the main stage, and $k_{\mathrm{m}}$ denotes main spring stiffness. According to the standard orifice equation, the flow through the main can be expressed as

$$
q_{\mathrm{m}}=C_{\mathrm{dm}} \omega_{\mathrm{m}} x_{\mathrm{m}} \sqrt{\frac{2\left(p_{\mathrm{a}}-p_{\mathrm{b}}\right)}{\rho}},
$$

where $q_{\mathrm{m}}$ is the main flow, $C_{\mathrm{dm}}$ is the discharge coefficient of the main orifice, and $\omega_{\mathrm{m}}$ is the area gradient of the main orifice. Based on the main stage geometry, the area gradient of the main orifice can be calculated as

$$
\omega_{\mathrm{m}}=\pi d_{\mathrm{m}} \sin \frac{\alpha}{2}\left(1-\frac{x_{\mathrm{m}}}{2 d_{\mathrm{m}}} \sin \alpha\right),
$$

where $d_{\mathrm{m}}$ denotes the diameter of the main stage seat and $\alpha$ denotes the cone angle of the poppet.

In the Valvistor valve, the pilot flow converges with the main flow at the outlet. Thus, the total flow through the Valvistor valve can be calculated as

$$
q_{\mathrm{t}}=q_{\mathrm{p}}+q_{\mathrm{m}}
$$

where $q_{\mathrm{t}}$ is the total flow through the Valvistor valve.

Employing Eqs. (1)-(7), the system model of the Valvistor valve can be written as 


$$
\begin{aligned}
& {\left[\begin{array}{c}
0 \\
0 \\
\dot{x}_{\mathrm{m}} \\
\ddot{x}_{\mathrm{m}}
\end{array}\right]=\left[\begin{array}{c}
C_{\mathrm{ds}} \omega_{\mathrm{s}}\left(x_{\mathrm{o}}+x_{\mathrm{m}}\right) \sqrt{\frac{2\left(p_{\mathrm{a}}-p_{\mathrm{c}}\right)}{\rho}}-C_{\mathrm{dp}} \omega_{\mathrm{p}} x_{\mathrm{p}} \sqrt{\frac{2\left(p_{\mathrm{c}}-p_{\mathrm{b}}\right)}{\rho}} \\
\frac{A_{\mathrm{a}} p_{\mathrm{a}}+\left(A_{\mathrm{c}}-A_{\mathrm{a}}\right) p_{\mathrm{b}}-A_{\mathrm{c}} p_{\mathrm{c}}}{m_{\mathrm{m}}}-\frac{B_{\mathrm{m}}}{m_{\mathrm{m}}} \dot{x}_{\mathrm{m}}-\frac{k_{\mathrm{m}}}{m_{\mathrm{m}}} x_{\mathrm{m}}
\end{array}\right]+\left[\begin{array}{c}
k_{\mathrm{e}} \\
0 \\
0 \\
0
\end{array}\right] u,} \\
& q_{\mathrm{t}}=C_{\mathrm{dp}} \omega_{\mathrm{p}} x_{\mathrm{p}} \sqrt{\frac{2\left(p_{\mathrm{c}}-p_{\mathrm{b}}\right)}{\rho}}+C_{\mathrm{dm}} \omega_{\mathrm{m}} x_{\mathrm{m}} \sqrt{\frac{2\left(p_{\mathrm{a}}-p_{\mathrm{b}}\right)}{\rho}}, \quad c_{2}=-\frac{2 C_{\mathrm{dp}}^{2} \omega_{\mathrm{p}}^{2}\left(p_{\mathrm{c} 0}-p_{\mathrm{b}}\right) x_{\mathrm{p} 0}}{C_{\mathrm{dp}}^{2} \omega_{\mathrm{p}}^{2} x_{\mathrm{p} 0}^{2}+C_{\mathrm{dm}}^{2} \omega_{\mathrm{m}}^{2} x_{\mathrm{m} 0}^{2}}=-\frac{\left(p_{\mathrm{a}}-p_{\mathrm{c} 0)\left(p_{\mathrm{c} 0}-p_{\mathrm{b}}\right)}^{x_{\mathrm{p} 0}\left(p_{\mathrm{a}}-p_{\mathrm{b}}\right)},\right.}{},
\end{aligned}
$$

To linearize the system model, define

$$
\begin{aligned}
& x_{\mathrm{p}}=x_{\mathrm{p} 0}+\Delta x_{\mathrm{p}}, \\
& p_{\mathrm{c}}=p_{\mathrm{c} 0}+\Delta p_{\mathrm{c}}, \\
& x_{\mathrm{m}}=x_{\mathrm{m} 0}+\Delta x_{\mathrm{m}}, \\
& \dot{x}_{\mathrm{m}}=\dot{x}_{\mathrm{m} 0}+\Delta \dot{x}_{\mathrm{m}}, \\
& q_{\mathrm{t}}=q_{\mathrm{t} 0}+\Delta q_{\mathrm{t}},
\end{aligned}
$$

Then the linearized model can be derived as

$$
\begin{aligned}
& {\left[\begin{array}{c}
0 \\
0 \\
\Delta \dot{x}_{\mathrm{m}} \\
\Delta \ddot{x}_{\mathrm{m}}
\end{array}\right]=\left[\begin{array}{cccc}
-1 & 0 & 0 & 0 \\
c_{1} & -1 & c_{2} & 0 \\
0 & 0 & 0 & 1 \\
0 & -\frac{A_{\mathrm{c}}}{m_{\mathrm{m}}} & -\frac{k_{\mathrm{m}}}{m_{\mathrm{m}}} & -\frac{B_{\mathrm{m}}}{m_{\mathrm{m}}}
\end{array}\right]\left[\begin{array}{c}
\Delta x_{\mathrm{p}} \\
\Delta p_{\mathrm{c}} \\
\Delta x_{\mathrm{m}} \\
\Delta \dot{x}_{\mathrm{m}}
\end{array}\right]+\left[\begin{array}{c}
\frac{k_{\mathrm{e}}}{k_{\mathrm{p}}} \\
0 \\
0 \\
0
\end{array}\right] \Delta u,} \\
& \Delta q_{\mathrm{t}}=c_{3} \Delta x_{\mathrm{p}}+c_{4} \Delta p_{\mathrm{c}}+c_{5} \Delta x_{\mathrm{m}},
\end{aligned}
$$

where the coefficients are

$$
c_{1}=\frac{2 C_{\mathrm{dm}}^{2} \omega_{\mathrm{m}}^{2}\left(p_{\mathrm{a}}-p_{\mathrm{c} 0}\right) x_{\mathrm{m} 0}}{C_{\mathrm{dp}}^{2} \omega_{\mathrm{p}}^{2} x_{\mathrm{p} 0}^{2}+C_{\mathrm{dm}}^{2} \omega_{\mathrm{m}}^{2} x_{\mathrm{m} 0}^{2}}=\frac{\left(p_{\mathrm{a}}-p_{\mathrm{c} 0}\right)\left(p_{\mathrm{c} 0}-p_{\mathrm{b}}\right)}{x_{\mathrm{m} 0}\left(p_{\mathrm{a}}-p_{\mathrm{b}}\right)},
$$

$$
\begin{aligned}
& c_{3}=C_{\mathrm{dp}} \omega_{\mathrm{p}} \sqrt{\frac{2\left(p_{\mathrm{c} 0}-p_{\mathrm{b}}\right)}{\rho},} \\
& c_{4}=\frac{C_{\mathrm{dp}} \omega_{\mathrm{p}} x_{\mathrm{p} 0}}{\sqrt{2 \rho\left(p_{\mathrm{c} 0}-p_{\mathrm{b}}\right)}}, \\
& c_{5}=C_{\mathrm{dm}} \omega_{\mathrm{m}} \sqrt{\frac{2\left(p_{\mathrm{a}}-p_{\mathrm{b}}\right)}{\rho}},
\end{aligned}
$$

Employing the Laplace transform, Eqs. (15) and (16) can be transformed as

$$
k_{\mathrm{p}} \Delta X_{\mathrm{p}}(s)-k_{\mathrm{e}} \Delta U(s)=0,
$$

$$
c_{1} \Delta X_{\mathrm{p}}(s)-\Delta P_{\mathrm{c}}(s)+c_{2} \Delta X_{\mathrm{m}}(s)=0,
$$

$$
\Delta X_{\mathrm{m}}(s) s^{2}+\frac{B_{\mathrm{m}}}{m_{\mathrm{m}}} \Delta X_{\mathrm{m}}(s) s+\frac{k_{\mathrm{m}}}{m_{\mathrm{m}}} \Delta X_{\mathrm{m}}(s)=-\frac{A_{\mathrm{c}}}{m_{\mathrm{m}}} \Delta P_{\mathrm{c}}(s),
$$

$$
\Delta Q_{\mathrm{t}}(s)=c_{3} \Delta X_{\mathrm{p}}(s)+c_{4} \Delta P_{\mathrm{c}}(s)+c_{5} \Delta X_{\mathrm{m}}(s) .
$$

As shown in Figure 2, the system model of the Valvistor valve can be presented as a block diagram. The transfer function can be derived as

$G_{\mathrm{v}}(s)=\frac{\Delta Q_{\mathrm{t}}(s)}{\Delta U(s)}=\frac{k_{\mathrm{e}}}{k_{\mathrm{p}}} \frac{\left(c_{3}+c_{1} c_{4}\right)\left(m_{\mathrm{m}} s^{2}+B_{\mathrm{m}} s+k_{\mathrm{m}}\right)+A_{\mathrm{c}}\left(c_{2} c_{3}-c_{1} c_{5}\right)}{m_{\mathrm{m}} s^{2}+B_{\mathrm{m}} s+k_{\mathrm{m}}+c_{2} A_{\mathrm{c}}}$

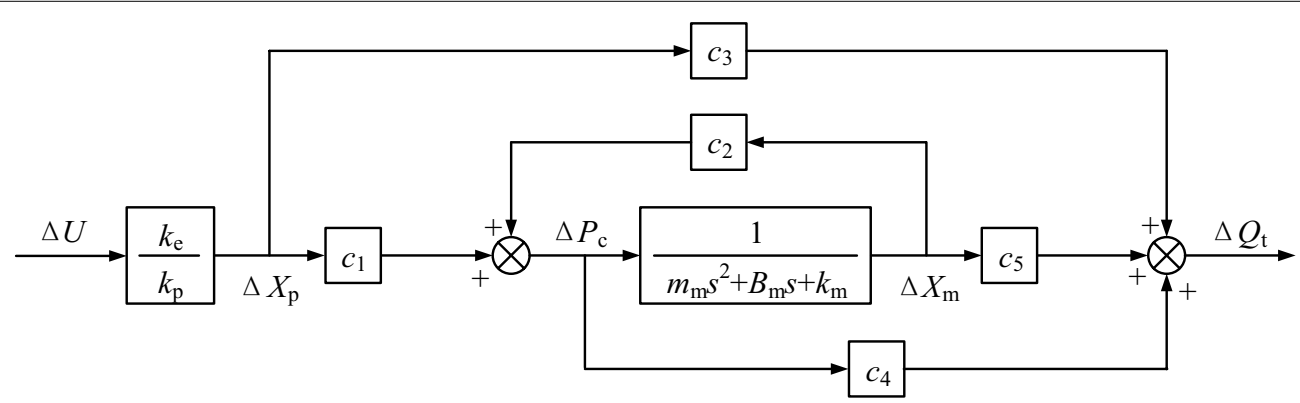

Figure 2 System model of the Valvistor valve 


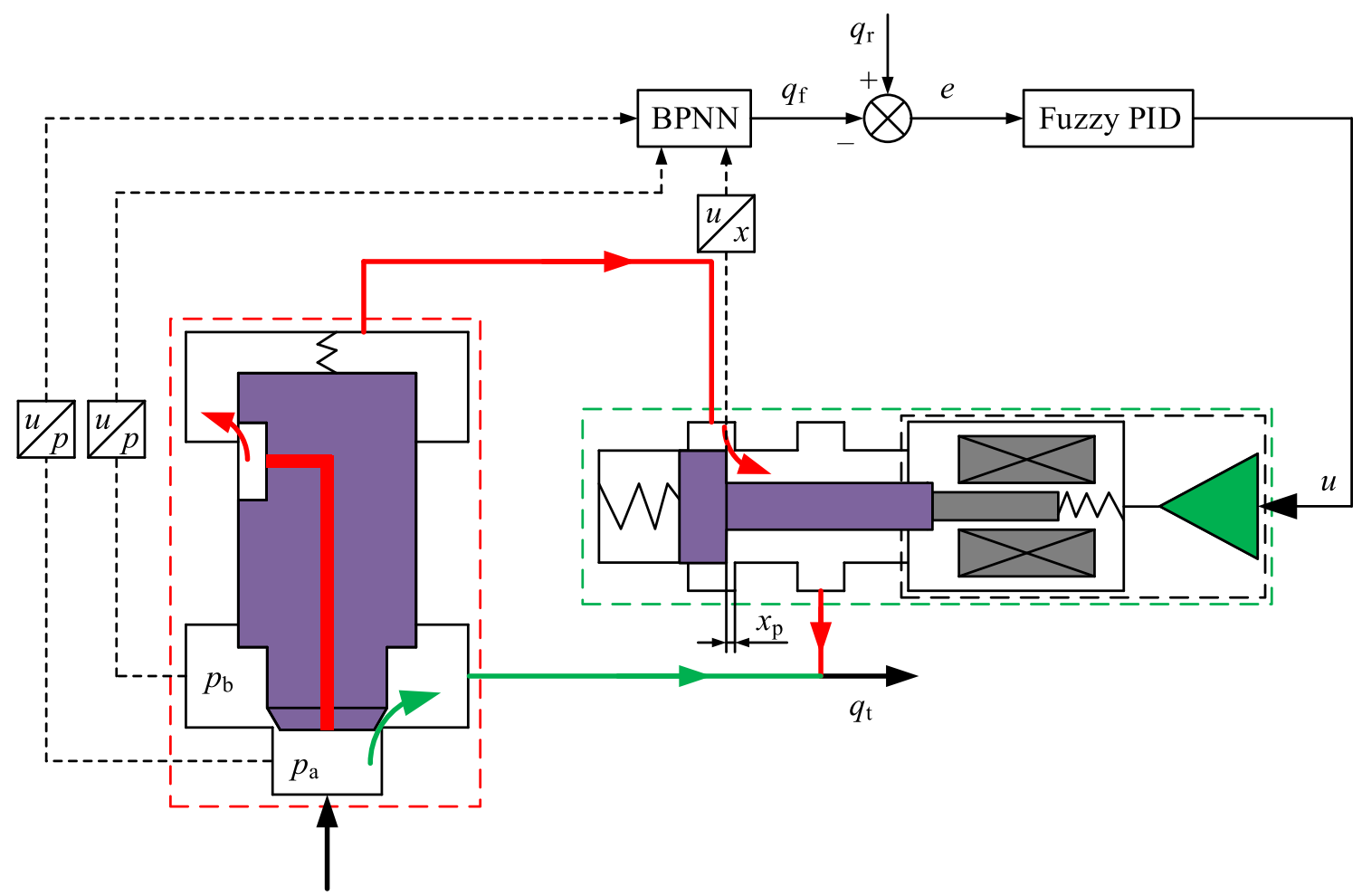

Figure 3 Flow control method for the Valvistor valve

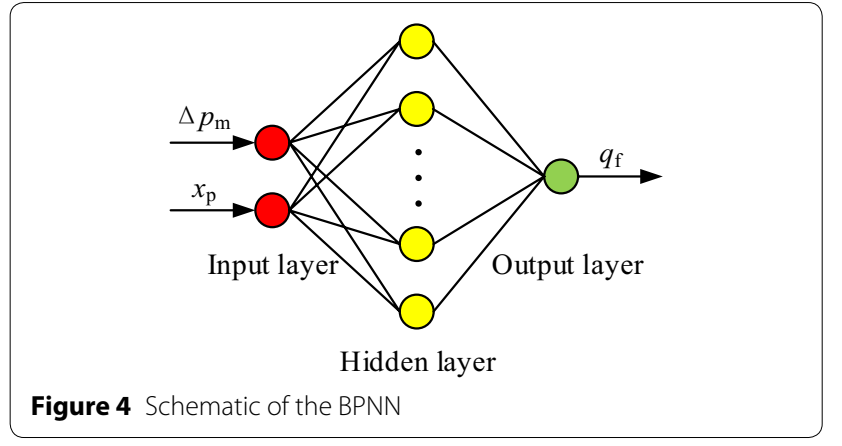

\section{Flow Control Method}

The flow control method for the Valvistor valve is shown in Figure 3. Fuzzy PID controller is adopt in the closedloop flow control system. The feedback is obtained by the flow inference with BPNN based on the spool displacement in the pilot stage and the pressure differential in the main stage. By this method, the flow is precisely controlled and unaffected by the change of load pressure. The transfer function is expressed as

$$
G(s)=\frac{Q_{\mathrm{t}}(s)}{Q_{\mathrm{r}}(s)}=\frac{G_{\mathrm{c}}(s) G_{\mathrm{v}}(s)}{1+G_{\mathrm{c}}(s) G_{\mathrm{v}}(s)} .
$$

\subsection{Establishment of BPNN Model}

The BPNN with three layers including an input layer, a hidden layer and an output layer is adopted to infer the flow. Based on the pressure differential across the main orifice $\Delta p_{\mathrm{m}}$ and the poppet displacement in the main stage $x_{\mathrm{m}}$, the flow through the Valvistor valve used as the feedback $q_{\mathrm{f}}$ can be predicted with the BPNN. As shown in Figure 4, there are two neurons labelled as $\Delta p_{\mathrm{m}}$ and $x_{\mathrm{m}}$ in the input layer and one neuron labelled as $q_{\mathrm{f}}$ in the output layer.

In the BPNN model, the error function for the output neuron is defined as

$$
E=\frac{1}{2}\left(p_{1}-z_{1}\right)^{2},
$$

where $E$ is the error function, $p_{1}$ is the inferred value of the output neuron, and $z_{1}$ is the actual value of the output 
neuron. The output of the hidden layer can be calculated as

$$
y_{j}=f_{\mathrm{y}}\left(\sum_{i=1}^{2} x_{i} w_{i j}+b_{j}\right),
$$

The output of the output layer can be expressed as

$$
z_{1}=f_{\mathrm{z}}\left(\sum_{j=1}^{n} y_{j} w_{j 1}+c_{1}\right),
$$

where $f_{\mathrm{y}}$ is the transfer function between the input layer and hidden layer, $f_{\mathrm{z}}$ is the transfer function between the hidden layer and output layer, $n$ is the number of neurons in the hidden layer, $w_{i j}$ is the weight between the input layer and hidden layer, $b_{j}$ is the threshold of the hidden layer, $w_{j 1}$ is the weight between the hidden layer and output layer, $c_{1}$ is the threshold of the output layer.

\subsection{Design of Fuzzy PID Controller}

The input voltage $u$ can be regulated by the Fuzzy PID controller based on the flow error $e$. For the fuzzy PID controller, the input is the flow error $e$ and the output is the voltage signal $u$. The schematic diagram of the fuzzy PID controller is shown in Figure 5. The fuzzy PID controller is composed by a fuzzy logic controller and a PID controller. The mathematical expression of the fuzzy PID controller can be written as

$$
u(t)=K_{\mathrm{P}} e(t)+K_{\mathrm{I}} \int_{0}^{t} e(t) \mathrm{d} t+K_{\mathrm{D}} \frac{\mathrm{d} e(t)}{\mathrm{d} t},
$$

where $e$ is the flow error, $K_{\mathrm{P}}$ is the proportion coefficient, $K_{\mathrm{I}}$ is the integral coefficient, and $K_{\mathrm{D}}$ is the derivative coefficient. Employing the Laplace transform, Eq. (31) can be transformed as

$$
U(s)=K_{\mathrm{P}} E(s)+\frac{K_{\mathrm{I}}}{s} E(s)+K_{\mathrm{D}} s E(s),
$$

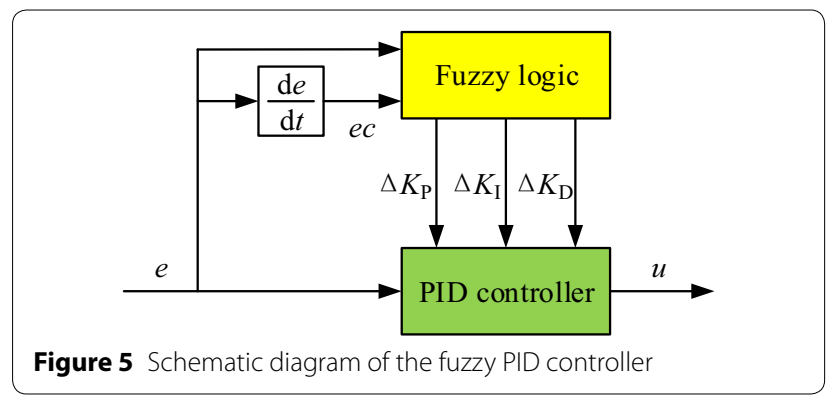

Consequently, the transfer function of the fuzzy PID controller can be written as

$$
G_{\mathrm{c}}(s)=\frac{U(s)}{E(s)}=\frac{K_{\mathrm{D}} s^{2}+K_{\mathrm{P}} s+K_{\mathrm{I}}}{s} .
$$

For the fuzzy logic controller, the inputs are the flow error $e$ and its change rate $e c$, and the outputs are the increments of PID coefficients $\Delta K_{\mathrm{P}}, \Delta K_{\mathrm{I}}$ and $\Delta K_{\mathrm{D}}$. Then, the PID coefficients $K_{\mathrm{P}}, K_{\mathrm{I}}$ and $K_{\mathrm{D}}$ can be expressed as

$$
\begin{aligned}
& K_{\mathrm{P}}=K_{\mathrm{P} 0}+\Delta K_{\mathrm{P}}, \\
& K_{\mathrm{I}}=K_{\mathrm{I} 0}+\Delta K_{\mathrm{I}}, \\
& K_{\mathrm{D}}=K_{\mathrm{D} 0}+\Delta K_{\mathrm{D}} .
\end{aligned}
$$

The fuzzy subset of the fuzzy linguistic variables $e, e c$, $\Delta K_{\mathrm{P}}, \Delta K_{\mathrm{I}}$ and $\Delta K_{\mathrm{D}}$ can be expressed as $\{\mathrm{NB}, \mathrm{NM}, \mathrm{NS}$, ZO, PS, PM, PB\}, where NB denotes negative big, NM denotes negative medium, NS denotes negative small, $\mathrm{ZO}$ denotes zero, PS denotes positive small, PM denotes positive medium and $\mathrm{PB}$ denotes positive big. In consideration of the control system of the Valvistor valve, the discourse universe of the fuzzy linguistic variables is selected as $\{-6,-5,-4,-3,-2,-1,0,1,2,3,4,5,6\}$. Gaussian function is employed as the membership function. By means of the weighted average method, the fuzzy reasoning is solved with simple calculation and the output is smooth.

\section{Experimental Apparatus}

As shown in Figure 6, the tested valve is fixed on the test bench. In order to measure the pressure differential across main orifice accurately, the pressure sensors are mounted on the main stage and pressure in the cavity is directly measured. Gear flow meters are applied to measure the flow through the tested valve and the pilot flow. The pilot stage is a single stage proportional valve, in which a linear variable differential transformer (LVDT) and its monitoring pin are integrated. The spool displacement can be measured by the LVDT and the data can be collected via the monitoring pin. Signals are sampled by means of the National Instrument (NI) PXI controller. The specifications of experimental setup are shown in Table 1 . The parameters of the tested valve are shown in Table 2.

\section{Results and Discussion}

In order to collect the training data, the flow is measured at different pressure differentials across the main orifice and the spool displacements in the pilot stage. The training data set for the inference of the flow is shown in Table 3. 


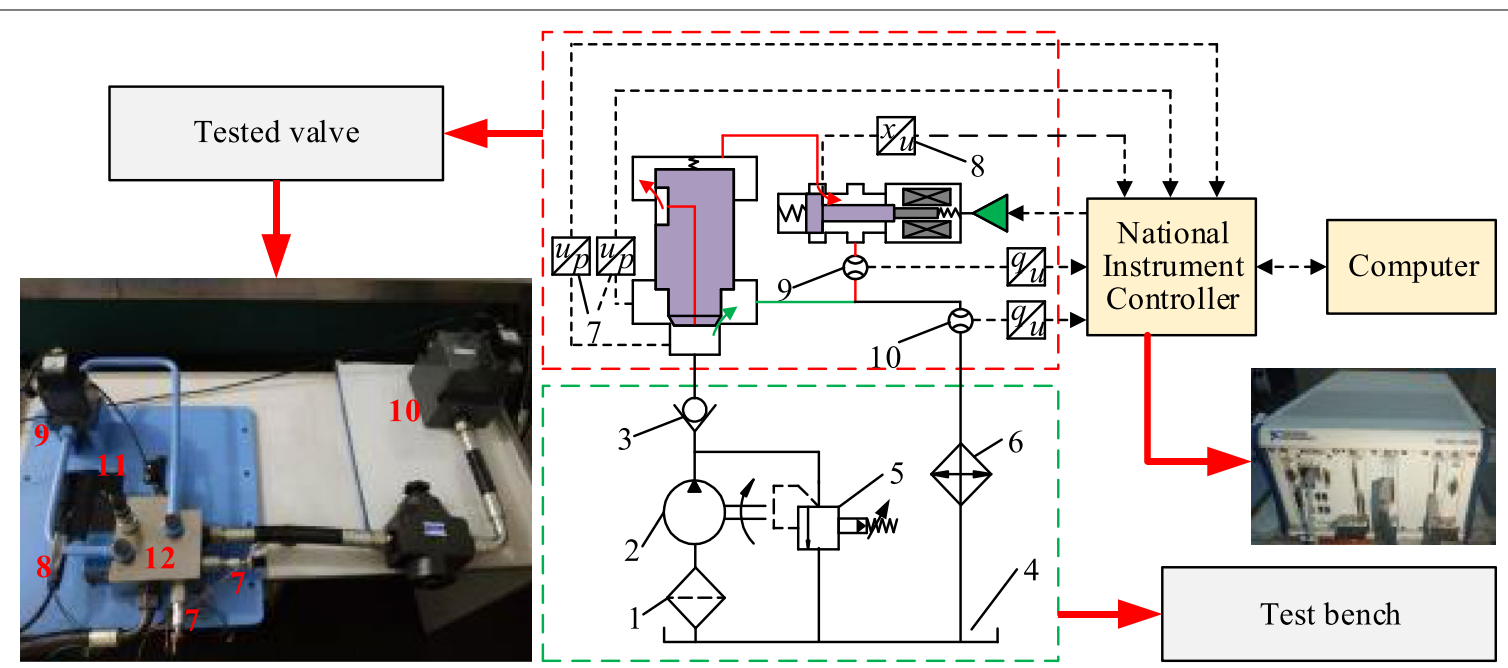

Figure 6 Experimental system of the Valvistor valve: 1. Filter, 2. Variable pump, 3. Check valve, 4. Oil tank, 5. Relief valve, 6. Cooler, 7. Pressure sensor, 8. Displacement sensor, 9. Flow meter for pilot flow, 10. Flow meter for total flow, 11. Pilot valve, 12. Main valve

Table 1 Specifications of experimental setup

\begin{tabular}{|c|c|c|c|c|}
\hline Device & Producer & Model number & Specification & \\
\hline Main valve & Vickers & EPV16 & & \\
\hline Pilot valve & Vickers & TG4V & & \\
\hline \multirow[t]{3}{*}{ Variable pump } & Bosch Rexroth & SYDFEE-20/100R & Rated pressure (MPa) & 28 \\
\hline & & & Rated speed (r/min) & 1450 \\
\hline & & & Maximum displacement $(\mathrm{mL} / \mathrm{r})$ & 100 \\
\hline \multirow[t]{3}{*}{ Pressure sensor } & Kistler & $4260 A 200$ & Full scale (MPa) & 20 \\
\hline & & & Maximum frequency response $(\mathrm{Hz})$ & 2000 \\
\hline & & & Measurement error & $0.05 \% \mathrm{FS}$ \\
\hline \multirow[t]{3}{*}{ Flow meter } & Parker & SCVF-150 & Full scale (L/min) & 20 \\
\hline & & & Response time (ms) & 150 \\
\hline & & & Measurement error & $0.5 \% \mathrm{FS}$ \\
\hline \multirow[t]{3}{*}{ Flow meter } & Parker & SCVF-15 & Full scale (L/min) & 15 \\
\hline & & & Response time (ms) & 20 \\
\hline & & & Measurement error & $0.5 \% \mathrm{FS}$ \\
\hline
\end{tabular}

Table 2 Parameters of the tested valve

\begin{tabular}{lcllll}
\hline Symbol & Value & Units & Symbol & Value & Units \\
\hline$k_{\mathrm{p}}$ & 20.2 & $\mathrm{~N} / \mathrm{mm}$ & $m_{\mathrm{m}}$ & 0.15 & $\mathrm{~kg}$ \\
$\omega_{\mathrm{p}}$ & 2.616 & $\mathrm{~mm}$ & $B_{\mathrm{m}}$ & 10 & $\mathrm{~N} \cdot \mathrm{s} / \mathrm{m}$ \\
$k_{\mathrm{e}}$ & 5.5 & $\mathrm{~N} / \mathrm{N}$ & $k_{\mathrm{m}}$ & 1 & $\mathrm{~N} / \mathrm{mm}$ \\
$d_{\mathrm{m}}$ & 14.14 & $\mathrm{~mm}$ & $x_{\mathrm{o}}$ & 0.42 & $\mathrm{~mm}$ \\
$a$ & 0.785 & $\mathrm{rad}$ & $\omega_{\mathrm{s}}$ & 1 & $\mathrm{~mm}$ \\
$A_{c}$ & 314.2 & $\mathrm{~mm}^{2}$ & $\rho$ & 870 & $\mathrm{~kg} / \mathrm{m}^{3}$ \\
$A_{\mathrm{a}}$ & 157.1 & $\mathrm{~mm}^{2}$ & & & \\
\hline
\end{tabular}

To find the proper number of the neurons in the hidden layer and ensure that the inference is accurate, comparisons between the inferred data and the measured data are performed at different numbers of the neurons in the hidden layer. The numbers of the neurons in the hidden layer are 2, 5, 10 and 15. Two typical cases are used to carry out the test on the performance of the BPNN model. In case 1 , the pressure differential across the main orifice $\Delta p_{\mathrm{m}}$ is constant at $2 \mathrm{MPa}$ and the spool displacement in the pilot stage $x_{\mathrm{p}}$ increases from 0.02 
Table 3 Training data set for the inference of the flow through the Valvistor valve

\begin{tabular}{|c|c|c|c|c|c|c|c|c|c|c|}
\hline \multirow[t]{2}{*}{$\Delta p_{\mathrm{m}}(\mathrm{MPa})$} & \multicolumn{10}{|c|}{$x_{p}(m m)$} \\
\hline & 0.02 & 0.04 & 0.06 & 0.08 & 0.10 & 0.12 & 0.14 & 0.16 & 0.18 & 0.20 \\
\hline 1 & 9.3 & 17.9 & 29.0 & 37.1 & 49.7 & 55.0 & 69.2 & 77.8 & 89.3 & 99.8 \\
\hline 2 & 12.6 & 25.5 & 38.6 & 54.5 & 67.2 & 79.7 & 98.1 & 112.6 & 126.8 & - \\
\hline 3 & 16.7 & 31.8 & 48.2 & 66.7 & 84.1 & 95.3 & 114.7 & 129.7 & - & - \\
\hline 4 & 19.3 & 36.7 & 59.1 & 72.4 & 100.0 & 114.6 & - & - & - & - \\
\hline 5 & 20.2 & 40.2 & 62.1 & 80.5 & 105.0 & 123.7 & - & - & - & - \\
\hline 6 & 22.0 & 45.9 & 67.4 & 91.8 & 114.3 & - & - & - & - & - \\
\hline 7 & 23.6 & 47.6 & 74.3 & 102.5 & 121.4 & - & - & - & - & - \\
\hline 8 & 26.8 & 52.0 & 80.5 & 108.0 & 129.4 & - & - & - & - & - \\
\hline 9 & 27.5 & 53.3 & 85.1 & 110.7 & - & - & - & - & - & - \\
\hline 10 & 29.0 & 57.9 & 87.2 & 121.9 & - & - & - & - & - & - \\
\hline 11 & 30.5 & 60.5 & 91.3 & 128.3 & - & - & - & - & - & - \\
\hline 12 & 31.6 & 63.8 & 95.3 & - & - & - & - & - & - & - \\
\hline 13 & 32.7 & 67.7 & 101.8 & - & - & - & - & - & - & - \\
\hline 14 & 34.1 & 68.8 & 105.4 & - & - & - & - & - & - & - \\
\hline 15 & 35.8 & 72.6 & 108.1 & - & - & - & - & - & - & - \\
\hline 16 & 37.1 & 75.2 & 110.8 & - & - & - & - & - & - & - \\
\hline
\end{tabular}

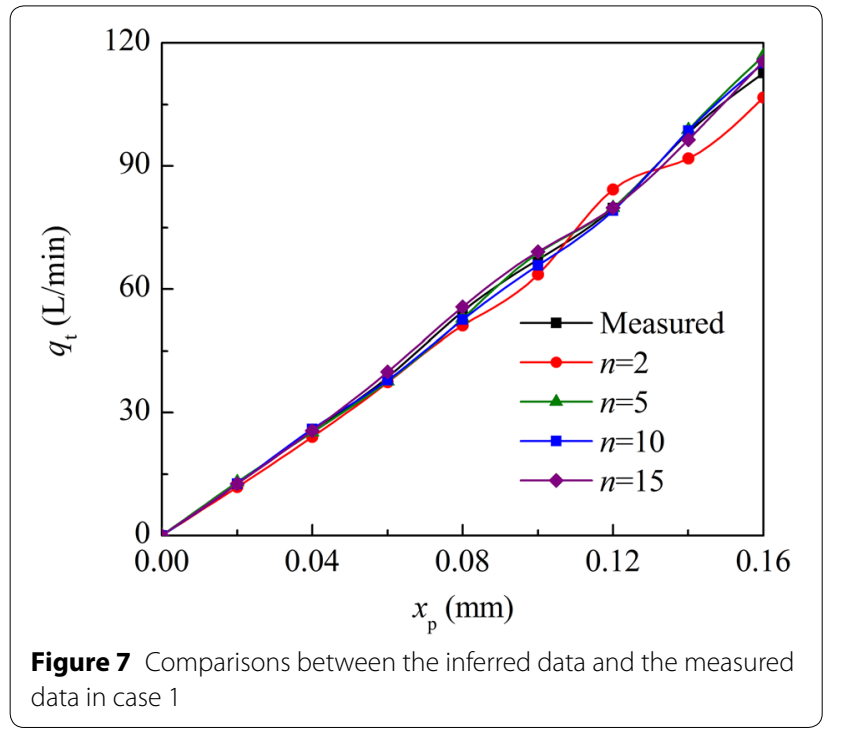

$\mathrm{mm}$ to $0.16 \mathrm{~mm}$ at increment of $0.02 \mathrm{~mm}$. In case 2 , the spool displacement in the pilot stage $x_{\mathrm{p}}$ is constant at 0.06 $\mathrm{mm}$ and the pressure differential across the main orifice $\Delta p_{\mathrm{m}}$ increases from $2 \mathrm{MPa}$ to $16 \mathrm{MPa}$ at increment of 2 $\mathrm{MPa}$. When the comparisons between the inferred data and the measured data in the two cases are shown in Figures 7 and 8 . The maximum errors between the inferred data and the measured data are listed in Table 4. Obviously, the change of the maximum error is very small as the number of the neurons in the hidden layer increases

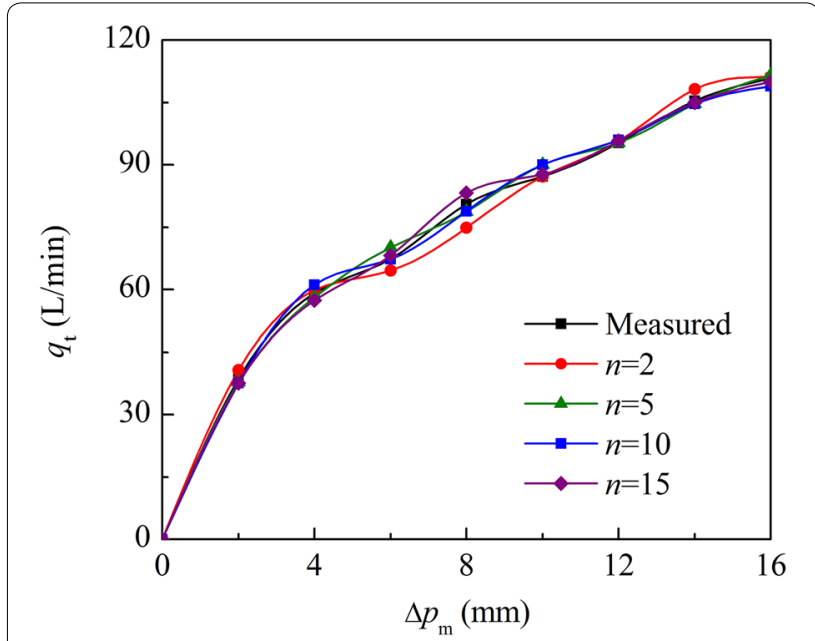

Figure 8 Comparisons between the inferred data and the measured data in case 2

Table 4 Maximum errors between the inferred data and the measured data

\begin{tabular}{lll}
\hline $\boldsymbol{n}$ & \multicolumn{2}{l}{ Maximum error (\%) } \\
\cline { 2 - 3 } & Case 1 & Case 2 \\
\hline 2 & 7.3 & 7.1 \\
5 & 4.0 & 3.9 \\
10 & 3.8 & 3.7 \\
15 & 3.6 & 3.6 \\
\hline
\end{tabular}




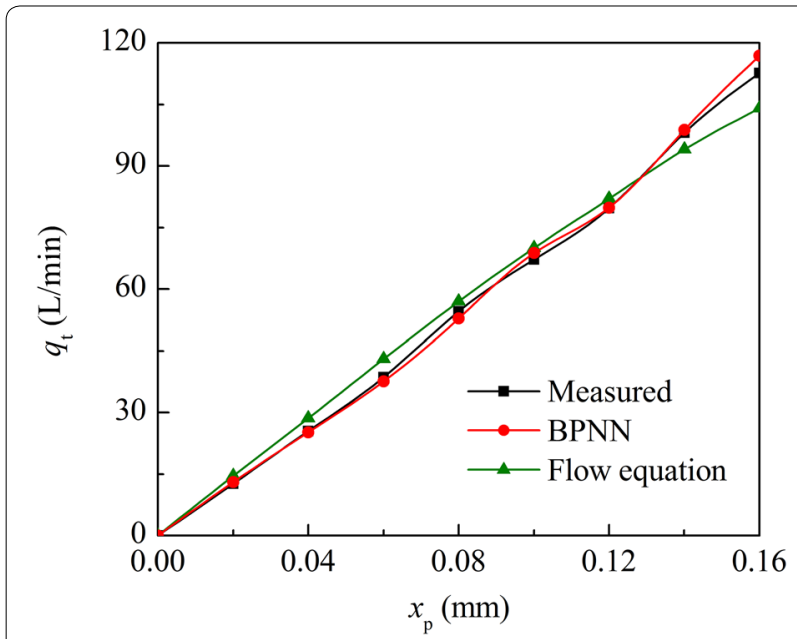

Figure 9 Comparisons between the inferred data and the computed data in case 1

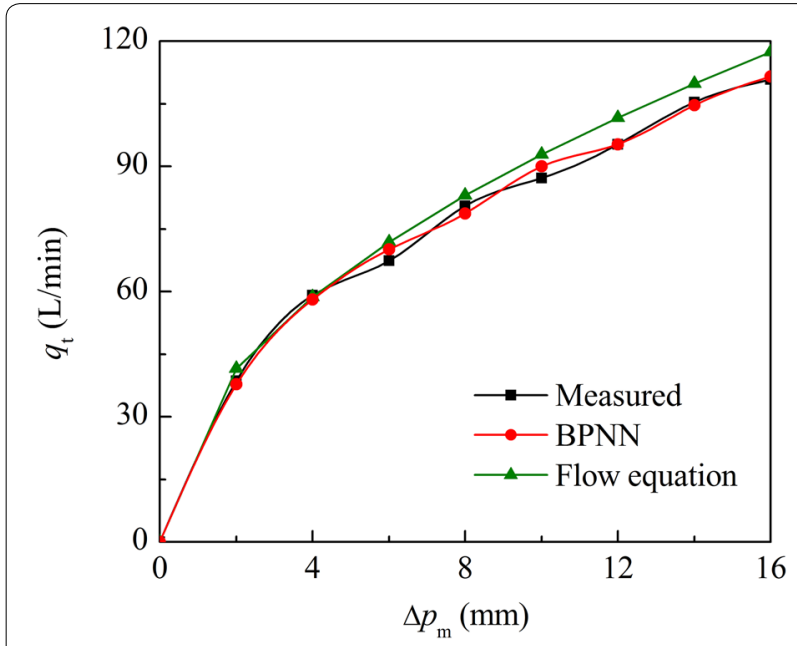

Figure 10 Comparisons between the inferred data and the computed data in case 2

from 5 to 15 . Therefore, the BPNN model with 5 neurons in the hidden layer is adequate in consideration of the inference accuracy and the computational effort.

The conventional method for the feedback flow acquisition is metering the pressure differential and poppet displacement, then the flow can be computed with the flow equation. Comparisons between the inferred data and the computed data in the two typical cases are shown in Figures 9 and 10. The maximum error between the inferred data and the measured data is about $4.0 \%$ while the maximum error between the computed data and the measured data is about $11.4 \%$. It can be found that

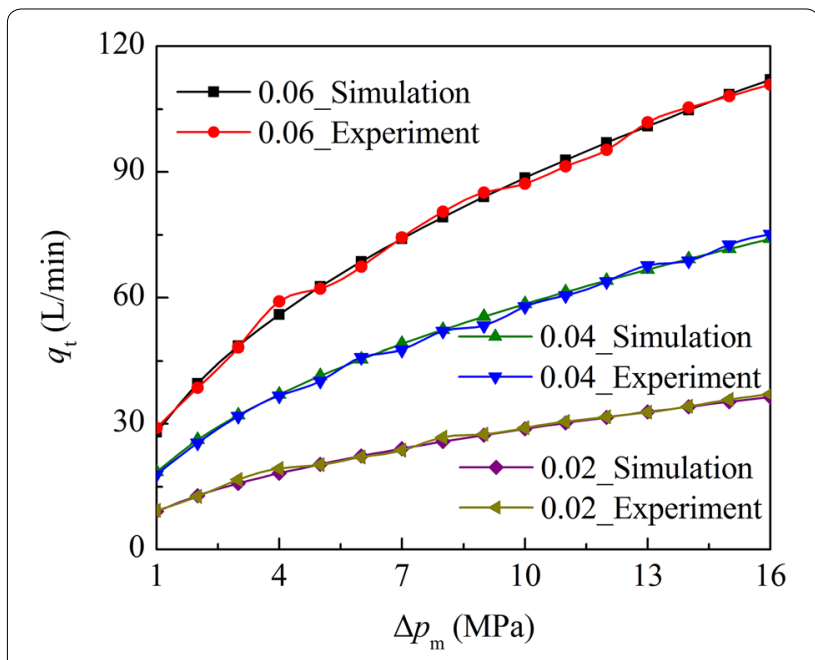

Figure 11 Flow without the flow control method

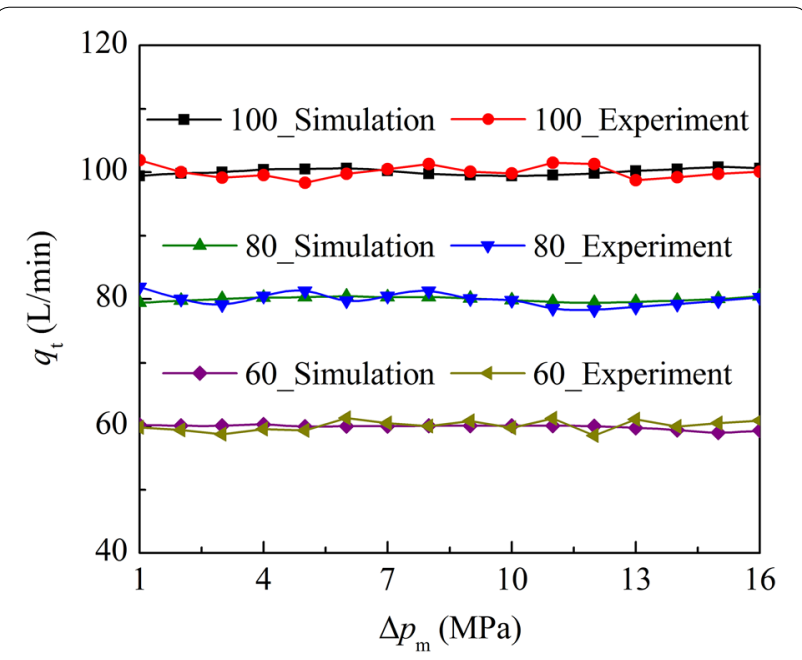

Figure 12 Flow with the flow control method

compared to the conventional flow equation, the BPNN can inferred the flow more accurately.

Without the flow control method, the spool displacement in the pilot stage is the controlled object. It can be seen from Figure 11 that when the pressure differential across the main orifice increases, the flow increase at a certain spool displacement in the pilot stage. Thus, without the flow control method, the Valvistor valve is a proportional throttle valve.

With the flow control method, the flow is the controlled object. As shown in Figure 12, when the pressure differential across the main orifice increases, the flow can keep at the set point. The maximum error between the experimental and setting values is $3.1 \%$. 


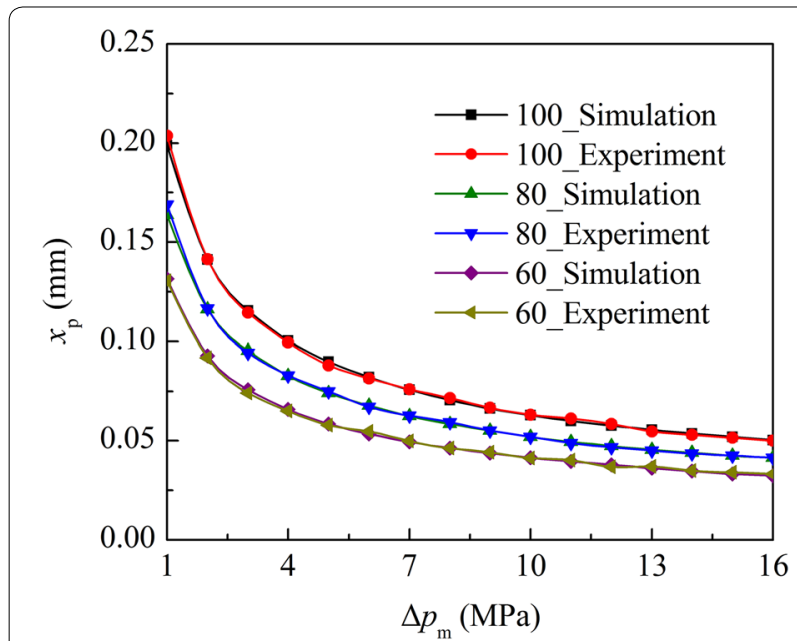

Figure 13 Spool displacements in the pilot stage with the flow control method

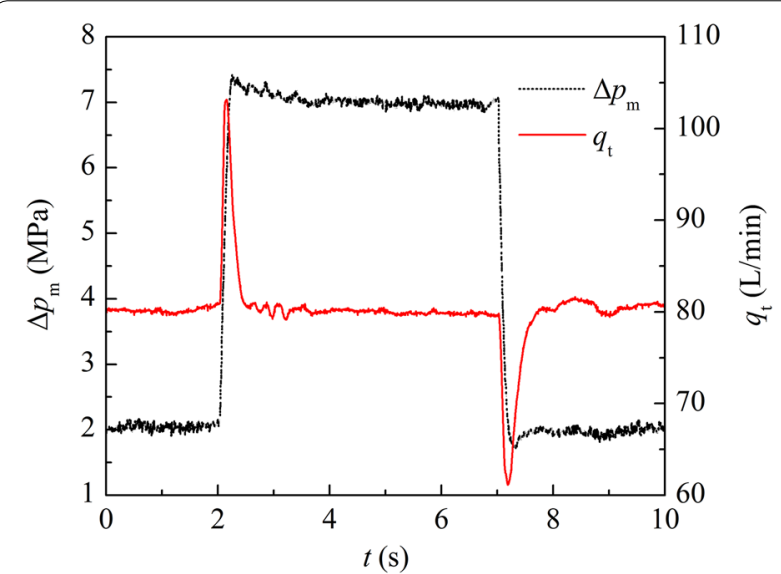

Figure 14 Flow through the developed valve at abrupt change of the load pressure

The spool displacements in the pilot stage with the flow control method are shown in Figure 13. When the pressure differential across the main orifice increases, the spool displacements in the pilot stage decrease. It can be seen from Figures 11, 12, 13 that the flow control method is very effective, with which the Valvistor valve changes from proportional throttle valve to proportional flow valve.

In Figures 11, 12, 13, the maximum error between the experimental and simulation values is $4.6 \%$. Thus, the linear mathematical model can be verified and the assumptions in the system modeling is reasonable.

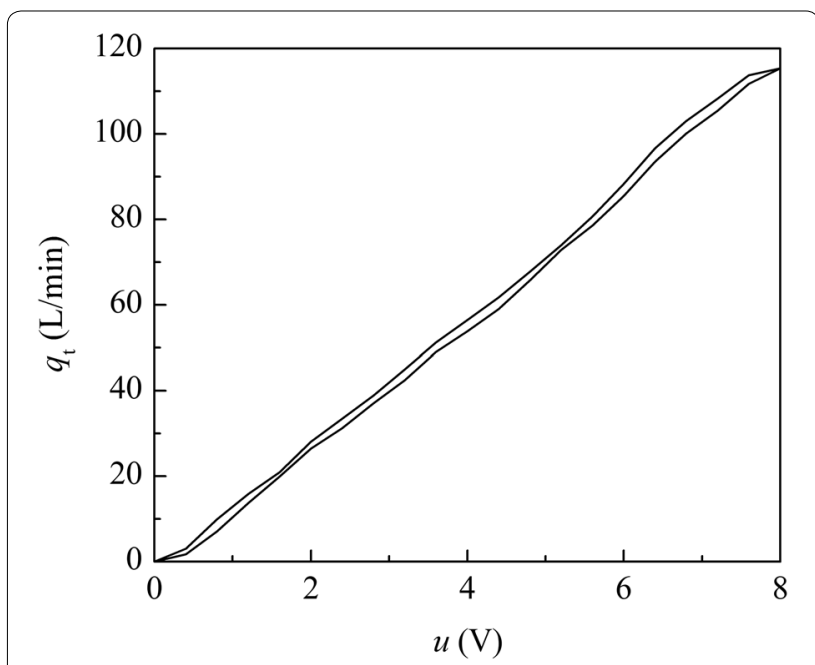

Figure 15 Flow characteristic of the developed valve

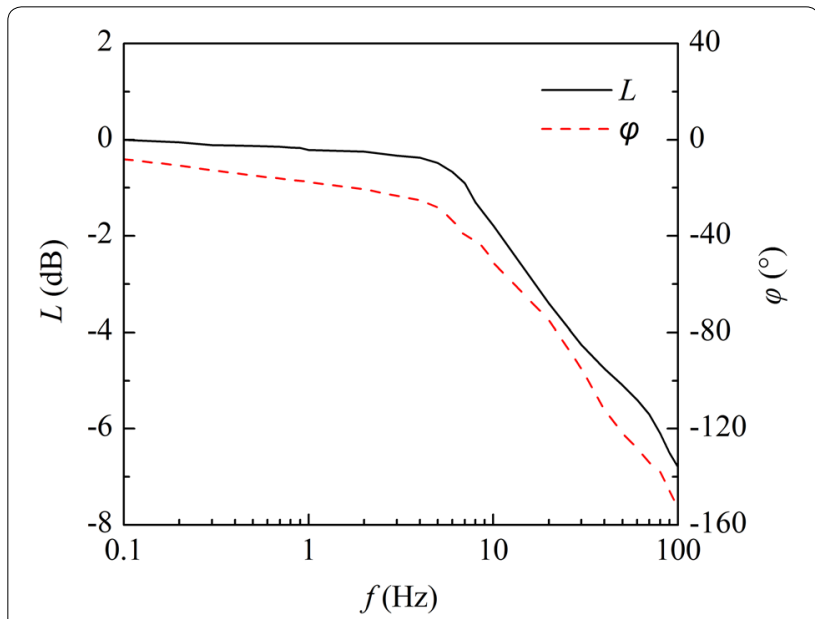

Figure 16 Frequency response of the developed valve

The performances of the developed valve are tested. The flow is measured when the pressure differential across the main orifice abruptly changes between $2 \mathrm{MPa}$ and $7 \mathrm{MPa}$. It can be seen from Figure 14 that the flow can maintain constant when the pressure differential across the main orifice abruptly changes. The flow is unaffected by the change of the load pressure. The overshoot is about $20 \mathrm{~L} / \mathrm{min}$ and the settling time is about $0.5 \mathrm{~s}$. The flow characteristic is measured when the input voltage circulate between $0 \mathrm{~V}$ and $8 \mathrm{~V}$. It can be calculated from Figure 15 that the hysteresis of the developed valve is less than $4.6 \%$ and the nonlinearity of the flow is less than $5.3 \%$. The frequency response of the Valvistor valve is measured when the frequency of the input voltage increases from $0.1 \mathrm{~Hz}$ 
to $100 \mathrm{~Hz}$. It can be seen from Figure 16 that the bandwidth of the developed valve is about $18 \mathrm{~Hz}$. Thus, with the flow control method, a high performance two-stage proportional flow valve based on the Valvistor valve is developed.

\section{Conclusions}

In this paper, a novel flow control method for a twostage proportional valve with hydraulic position feedback which is named as Valvistor valve is provided to develop a high performance proportional flow valve. The mathematical model of this valve is established and linearized. Fuzzy PID controller is adopt in the closedloop flow control system. The feed-back is obtained by the flow inference with BPNN based on the spool displacement in the pilot stage and the pressure differential across the main orifice.

(1) With BPNN, the inferred data is very close to the measured data. Therefore, inference with BPNN can obtain the flow data fast and accurately.

(2) With the flow control method, the flow can keep at the set point when the pressure differential across the main orifice changes. Therefore, the flow control method is effective and the Valvistor valve changes from proportional throttle valve to proportional flow valve.

(3) For the developed proportional flow valve, the settling time of the flow is very short when the load pressure changes abruptly. Thus, the flow is unaffected by the change of the load pressure.

(4) The performances of hysteresis, linearity and bandwidth are in a high range. Thus, with the flow control method, a high performance two-stage proportional flow valve based on the Valvistor valve is developed.

(5) The simulation results are close to the test results. Therefore, the linear mathematical model can be verified and the assumptions in the system modeling is reasonable.

\section{Acknowledgements \\ Not applicable.}

\section{Authors' Contributions}

HW performed the system modelling, designed the controller, and wrote the manuscript. XW built the experiment and tested the valve performance. JH conducted the simulation. LQ was in charge of the whole project and directed the studies. All authors read and approved the final manuscript.

\section{Authors' Information}

He Wang, born in 1986, is currently an associate professor at Key Laboratory of Advanced Transducers and Intelligent Control System, Ministry of Education, Taiyuan University of Technology, China. He is a postdoctoral fellow at Shanxi Transportation Technology Research \& Development Co., Ltd, China. His research interests include the hydraulic components and systems.
Xiaohu Wang, born in 1990, is currently a master candidate at Key Laboratory of Advanced Transducers and Intelligent Control System, Ministry of Education,

Taiyuan University of Technology, China. His research interest is Hydraulic valves.

Jiahai Huang, born in 1979, is currently a professor at Key Laboratory of Advanced Transducers and Intelligent Control System, Ministry of Education, Taiyuan University of Technology, China. His research interests is electro-hydraulic proportional control technology.

Long Quan, born in 1959, is currently a professor at Key Laboratory of Advanced Transducers and Intelligent Control System, Ministry of Education, Taiyuan University of Technology, China. His research interests include fluid power transmission and control.

\section{Funding}

Supported by National Natural Science Foundation of China (Grant No. 51805350), Key Technologies Research and Development Program of China (Grant No. 2018YFB2001202), Natural Science Foundation of Shanxi Province of China (Grant No. 201801D221226), and Postdoctoral Science Foundation of China (Grant No. 2019M651073).

\section{Competing Interests}

The authors declare no competing financial interests.

\section{Author Details}

${ }^{1}$ Key Laboratory of Advanced Transducers and Intelligent Control System, Ministry of Education, Taiyuan University of Technology, Taiyuan 030024,

China. ${ }^{2}$ Shanxi Transportation Technology Research \& Development Co., Ltd, Taiyuan 030024, China.

Received: 2 January 2020 Revised: 5 November 2020 Accepted: 18 November 2020

Published online: 04 December 2020

\section{References}

[1] PTamburrano, A R Plummer, E Distaso, et al. A review of direct drive proportional electrohydraulic spool valves: industrial state-of-the-art and research advancements. Journal of Dynamic Systems Measurement and Control-Transactions of the ASME, 2019, 141(2): 020801.

[2] J Zhang, D Wang, B Xu, et al. Flow control of a proportional directional valve without the flow meter. Flow Measurement and Instrumentation, 2019, 67: 131-141.

[3] U Pal, G Mukhopadhyay, S Bhattacharya. Failure analysis of spring of hydraulic operated valve. Engineering Failure Analysis, 2018, 95: 191-198.

[4] $\mathrm{YLXu}, \mathrm{HW}$ Nie, H L Zhao, et al. Mathematical modelling and simulation of a novel hydraulic variable valve timing system. International Journal of Simulation Modelling, 2020, 19(2): 303-312.

[5] D Prsic, C Fragassa, N Nedic, et al. Describing function of the pneumatic flapper-nozzle valve. Mechanical Systems and Signal Processing, 2019, 124 : 696-714.

[6] XXiong, J Huang. Performance of a flow control valve with pilot switching valve. Proceedings of the Institution of Mechanical Engineers Part I-Journal of Systems and Control Engineering, 2018, 232(2): 178-194.

[7] SH Park. Development of a proportional poppet type water hydraulic valve. Proceedings of the Institution of Mechanical Engineers, Part C-Journal of Mechanical Engineering Science, 2009, 223(9): 2009-2107.

[8] L Quan, X Xu, Z Yan, et al. A new kind of pilot controlled proportional direction valve with internal flow feedback. Chinese Journal of Mechanical Engineering, 2010, 23(1): 60-65.

[9] Z Wang, HWu, D Gao, et al. Distribution performance analysis and experimental research on the port plate pairs of low speed high torque seawater hydraulic motor. Chinese Journal of Mechanical Engineering, 2019, 32: 108

[10] Y Liu, TWang, G Gong, et al. Present status and prospect of high-frequency electro-hydraulic vibration control technology. Chinese Journal of Mechanical Engineering, 2019, 32: 93. 
[11] B Xu, Q Su, J Zhang, et al. Analysis and compensation for the cascade dead-zones in the proportional control valve. ISA Transactions, 2017, 66: 393-403.

[12] H Shi, H Yang, G Gong, et al. Energy saving of cutterhead hydraulic drive system of shield tunneling machine. Automation in Construction, 2014, 37: $11-21$.

[13] L Ge, L Quan, X Zhang, et al. Power matching and energy efficiency improvement of hydraulic excavator driven with speed and displacement variable power source. Chinese Journal of Mechanical Engineering, 2019, 32: 100.

[14] B Eriksson, J Larsson, J O Palmberg. A novel valve concept including the Valvistor poppet valve. 10th Scandinavian International Conference on Fluid Power, 2008: 438-445.

[15] Y Hao, L Quan, J Huang. Research on the performance of electro-hydraulic proportional flow valve controlled by active pilot pump. Proceedings of the Institution of Mechanical Engineers, Part E-Journal of Process Mechanical Engineering, 2015, 231(4): 1989-1996.

[16] J Huang, J Dai, L Quan, et al. Performance of proportional flow valve with pilot pressure differential-spool opening compensation. Journal of Dynamic Systems Measurement and Control-Transactions of the ASME, 2017, 139: 011009.

[17] J Huang, X Wang, H Wang, et al. Development of a flow control valve with digital flow compensator. Flow Measurement and Instrumentation, 2019, 66: $157-169$.

[18] J Zhang, Y Deng, N Zhang, et al. Vibration performance analysis of a mining vehicle with bounce and pitch tuned hydraulically interconnected suspension. Chinese Journal of Mechanical Engineering, 2019, 32: 5

[19] R M Asl, Y S Hagh, S Simani, et al. Adaptive square-root unscented Kalman filter: An experimental study of hydraulic actuator state estimation. Mechanical Systems and Signal Processing, 2019, 132: 670-691.

[20] S Li, C Li, Z Li, et al. Design optimization and experimental performance test of dynamic flow balance valve. Engineering Applications of Computational Fluid Mechanics, 2020, 14(1): 700-712.

[21] W Deng, J Yao, D Ma. Robust adaptive precision motion control of hydraulic actuators with valve dead-zone compensation. ISA Transactions, 2017, 70: 269-278.

[22] Y Xu, X Liu, J Xu. Research on the Structural Rigidity Characteristics of a Reconfigurable TBM Thrust Mechanism. Chinese Journal of Mechanical Engineering, 2019, 32:107.
[23] Z Jia, J Ma, F Wang, et al. Characteristics prediction method of electrohydraulic servo valve based on rough set and adaptive neuro-fuzzy inference system. Chinese Journal of Mechanical Engineering, 2010, 23: 200-208.

[24] A O Ibrahim, A M Shamsuddin, A Abraham, et al. Adaptive memetic method of multi-objective genetic evolutionary algorithm for backpropagation neural network. Neural Computing and Applications, 2019, 31 : 4945-4962

[25] S Daneshvar, K A Adesina. Modified variable return to scale back-propagation neural network robust parameter optimization procedure for multi-quality processes. Engineering Optimization, 2019, 51(8): 1352-1369.

[26] PY Kow, Y S Wang, Y Zhou, et al. Seamless integration of convolutional and back-propagation neural networks for regional multi-step-ahead PM2.5 forecasting. Journal of Cleaner Production, 2020, 261: 121285.

[27] Z Qu, W Mao, K Zhang, et al. Multi-step wind speed forecasting based on a hybrid decomposition technique and an improved back-propagation neural network. Renewable Energy, 2019, 133: 919-929.

[28] J Feng, W Wang, F Xu, et al. Estimating surface heat and water vapor fluxes by combining two-source energy balance model and backpropagation neural network. Science of the Total Environment, 2020, 729: 138724.

[29] G Magdy, E A Mohamed, G Shabib, et al. SMES based a new PID controller for frequency stability of a real hybrid power system considering high wind power penetration. IET Renewable Power Generation, 2018, 12(11): 1304-1313.

[30] A Rohan, F Asghar, S H Kim. Design of fuzzy logic tuned PID controller for electric vehicle based on IPMSM using flux-weakening. Journal of Electrical Engineering and Technology, 2018, 13(1): 451-459.

[31] G Wart, M Bhola, P Ranjan, et al. Energy saving and Fuzzy-PID position control of electro-hydraulic system by leakage compensation through proportional flow control valve. ISA Transactions, 2020, 101: 269-280.

[32] S Cetin, A V Akkaya. Simulation and hybrid fuzzy-PID control for positioning of a hydraulic system. Nonlinear Dynamics, 2010, 61(3): 465-476.

[33] X Jin, K Chen, Y Zhao, et al. Simulation of hydraulic transplanting robot control system based on fuzzy PID controller. Measurement, 2020, 164: 108023.

\section{Submit your manuscript to a SpringerOpen ${ }^{\circ}$ journal and benefit from:}

- Convenient online submission

- Rigorous peer review

- Open access: articles freely available online

- High visibility within the field

- Retaining the copyright to your article

Submit your next manuscript at springeropen.com 